\title{
VALOR FONÉTICO DAS VOGAIS MÉDIAS POSTÔNICAS EM JORNAIS OITOCENTISTAS GAÚCHOS
}

\author{
Valéria Neto de Oliveira Monaretto (UFRGS) ${ }^{1}$
}

\section{RESUMO}

Um dos problemas mais difíceis do vocalismo do português antigo é o valor fonético a ser atribuído às letras $\underline{e}$ e $\underline{o}$ quando não derivadas das formas tônicas do latim (NARO, 1973). Não há evidências diretas que atestem a realização dessas vogais como $[e, o]$ ou $[i, u]$ em português antigo. A ortografia revela ocorrências acidentais de registros variáveis, e as gramáticas dos séculos XVI, XVII e XVIII alertam sobre a relação estreita dessas letras. Conforme Câmara Jr (1975b), no português brasileiro moderno, as sete vogais /a, e, $\varepsilon$, o, o, u/ são reduzidas na posição postônica, em decorrência de um processo de neutralização entre vogais médias e vogais altas, condicionado prosodicamente. Entretanto, esse processo não é categórico no português brasileiro. Estudos sobre esse fenômeno fonológico na fala do sul do Brasil, sob a ótica da sociolinguística laboviana, revelam que a neutralização atua como uma regra variável, pois são encontradas realizações ora como vogais médias [e, o], ora como vogais altas $[\mathrm{i}, \mathrm{u}]$, como, por exemplo, nas formas pent [e], alternado com pent [i]; bordad[o], como bordad[u], entre outros. Com base em um levantamento grafemático das letras $\underline{e}$ e $\underline{o}$ em contexto postônico, o presente trabalho objetiva contribuir para a descrição de sincronias passadas da língua portuguesa através de possíveis registros de alteamento de vogais postônicas. A variação gráfica entre e/i e o/u em jornais oitocentistas sul rio-grandenses encontrada em periódicos não permitiu verificar o comportamento variável das vogais postônicas, pela escassez de dados. No entanto, há indícios grafológicos variáveis de alçamento em vogais pretônicas que evidenciam a instabilidade de realização das vogais médias átonas, que se encontra consolidada na norma escrita de vogais postônicas com $\underline{e}$ e $\operatorname{com} \underline{\underline{o}}$, desde muito tempo. Parece haver uma neutralização entre sons, manifestada pela opção da escolha de um só grafema.

PALAVRAS-CHAVE: Vogais Postônicas; Português Brasileiro Oitocentista. 


\begin{abstract}
One of the most difficult problems of the vocalism of the old portuguese is the phonetic value to be assigned to the letters $\underline{e}$ and $\underline{o}$ when not derived from the Latin tonic forms (Naro, 1973). There is no direct evidence attesting to the realization of these vowels $[e, o]$ or $[i, u]$ in former Portuguese. Spelling reveals accidental occurrences variable record, and the grammars of the sixteenth, seventeenth, eighteenth warn about the close relationship of these letters. As Câmara Jr (1975b), in modern Brazilian Portuguese, the seven vowels / a, e, $\varepsilon, o, o, u$ / are reduced in pos-tonic position, as a result of a neutralization process between middle vowels and high vowels, prosodically conditioned. However, this process is not categorical in Brazilian Portuguese. Studies on this phenomenon phonological speech of southern Brazil, from the perspective of sociolinguistics Labovian reveal that neutralization acts as a variable rule, because achievements are found either as mid vowels [e, o], sometimes as high vowels $[i, u]$, for example, in the forms pent[e], alternated with pent[i]; bordad[o], with bordad[u] among others. Based on a survey of the letters $e$ and $o$ post-tonic into context, this work aims to contribute to the description of synchronicities past the Portuguese language through records possible of heightening vowels post-tonics. The variation between graphical $\mathrm{e} / \mathrm{i}$ and $\mathrm{o} / \mathrm{u}$ in newspapers nineteenth century southern Rio Grande found in journals not possible to verify the behavior of the variable post-tonic vowels, the scarcity of data. However, there is evidence graphological variables pre-tonics vowels show that the instability of realization of unstressed mid vowels, which is consolidated in the standard writing vowels post-tonics with $\underline{e}$ and with $\underline{\underline{o}}$, long time. There seems to be an offset between sounds, manifested by the option of choosing a single grapheme.
\end{abstract}

KEYWORDS: Post-tonic vowels; Portuguese Brazilian nineteenth century.

\title{
Introdução
}

Variáveis fonológicas do português brasileiro têm sido estudadas, na maioria das pesquisas, sob a perspectiva da sociolinguística laboviana, com dados da fala. Ainda são poucos os estudos de sincronias passadas na área de fonologia e, em especial, sobre a variedade do Rio Grande do Sul, que é de colonização mais tardia no Brasil, mas já com história de mais de três séculos.

A memória linguística gaúcha está registrada sob forma de manuscritos e documentos a partir do final do século XVIII e de um grande número de jornais variados desde 1827. A ortografia em jornais, apesar de ser uma fonte impressa, pode sinalizar a existência de processos fonológicos (NASI, 2012), porém é preciso estabelecer previamente uma taxonomia que separe os tipos de alterações ortográficas existentes. Para citar alguns exemplos, há alterações ortográficas decorrentes de representações múltiplas (caza por casa); transcrição da fala (despois por depois); etimologia (oje por hoje); generalizações (enteiro por inteiro); segmentação indevida (de mais por demais); troca de letras (sabemdo por sabendo); relações segmentais (sau por sal), entre outros casos (MONARETTO, 2005). Problemas de 
representatividade do registro escrito não serão abordados neste trabalho, mas tentar-se-á fazer, nas palavras de Labov (1972, p.11), o melhor uso de dados ruins, com base no registro gráfico de jornais.

Segundo Naro (1973), um dos problemas mais difíceis do vocalismo do português antigo é o valor fonético a ser atribuído às letras $\underline{e}$ e $\underline{o}$ quando não derivadas das formas tônicas do latim. Muitas das observações realizadas na variação de grafia de palavras, encontradas em textos de português até o século XVIII, são impressionistas e arbitrárias. O exame da grafia em textos não atesta com precisão, realizações fonéticas de segmentos, o que dificulta ainda mais a investigação diacrônica de algum processo fonológico.

Apesar das dificuldades encontradas em uma investigação dessa natureza, este trabalho propõe estudar alguns aspectos relacionados ao valor fonético das vogais postônicas do português oitocentista do Rio Grande do Sul a partir de levantamento de registros de $\underline{i}$ e $\underline{u}$ no lugar, respectivamente, de $\underline{e}$ e $\underline{o}$, em jornais. As observações sobre o valor fonético das vogais átonas na escrita baseiam-se em descrições sobre o comportamento variável na língua falada do português brasileiro moderno do sul do Brasil, com o objetivo de se refletir sobre o processo de mudança fonológica das vogais postônicas no português brasileiro, em especial, na variedade gaúcha.

Para tanto, este trabalho foi dividido como segue. Na primeira seção, serão apresentadas algumas observações históricas sobre a representação fonética das vogais /e/ e /o/, no português antigo, segundo a literatura. Na segunda seção, abordar-se-á o tratamento dado às vogais postônicas pela visão do linguista Joaquim Mattoso Câmara Jr. e por pesquisadores sociolinguistas labovianos. Na terceira e última seção, serão apresentados dados escritos de registros de palavras em jornais do Rio Grande do Sul com vogais i/u no lugar de e/o da ortografia moderna e algumas interpretações preliminares.

\section{Observações Sobre o Valor Fonético das Vogais /e/ e /o/ átonas}

\subsection{Na história da Língua Portuguesa}

Como as vogais médias átonas, grafadas com as letras $\underline{o}$ e $\underline{e}$ no português brasileiro moderno são variáveis, ora pronunciadas com som de [u] e [i], ora com som de [o] e [e], respectivamente, em palavras como bolo e leite, por exemplo, a questão que se coloca é: que valor fonético possuíam na história do português? A variação, que há hoje, tem início em que época?

Segundo Marquilhas (2003), são medievais as primeiras grafias que provam a ocorrência de vogais altas em sílaba final não acentuada. A redução nas postônicas finais apresenta-se hoje sistematicamente integrada na do vocalismo pretônico do português europeu.

Conforme Naro (1973), não há evidências diretas que atestem a realização das vogais $\underline{e}$ e $\underline{o}$ como $[e, o]$ ou $[i, u]$ em português antigo. A ortografia revela ocorrências acidentais de registros variá- 
veis desses segmentos, e as gramáticas do período clássico da língua portuguesa alertam sobre a relação estreita dessas letras. Há posicionamentos nada claros e, por vezes, contraditórios sobre a natureza fonética dessas realizações. Alguns consideram a realização de $\underline{e}$ e de $\underline{o}$ átonos como [e,u], desde o século XVI ou antes, baseando-se nas pronúncias modernas. Outros, como Herculano de Carvalho (1962) e Révah (1959), propõem a realização [i, u] ou [e,o], respectivamente.

Révah (1959), dentre outros, procura localizar na história o fenômeno de redução.

A pronúncia -i por -e átona final é confirmada em 1783 por Francisco Feles Carneiro Souto-Maior. Nos anos 1816 a 1819 Fr. Francisco dos Prazeres e Jerónimo Soares Barbosa, atribuem essas pronúncias aos brasileiros. (RÉvAH, 1959, p. 282)

Para Naro (op. cit. p. 15), encontram-se, na prática ortográfica em documentos anteriores a meados do século XIV, ocorrências acidentais das letras $\underline{i}$ e $\underline{u}$, onde se esperaria encontrar $\underline{e}$ e $\underline{o}$, como, por exemplo, duze por doze; fur por for, cum por com, sangui por sangue, aquiles por aqueles, etc. Alguns desses registros podem ser explicados pela influência do latim, mas outros não, pois sugerem que a vogal média se torna alta em qualquer posição.

Alguns casos observados são, sem dúvida, originados pela interferência do conhecimento da escrita latina. Porém, é interessante notar que a substituição de $\underline{o}$ por $\underline{u}$ é unidirecional, pois muitos dos casos de [o] do português correspondem ao $\underline{u}$ do latim, mas poucos dos de [u] do português correspondem ao $\underline{o}$ do latim. Apesar das controvérsias históricas, os gramáticos do século XVI, Oliveira, Barros e Nunez do Lião reconhecem também variedades para /e/ e /o/.

Naro (op. cit.) acredita que certos fatos encontrados em três línguas, geograficamente separadas (Português Metropolitano, Brasil e Ceilão), onde o português foi falado como língua nativa, constituem um caso clássico da deriva Sapiriana. Mudanças posteriores em relação às vogais postônicas /e, o/ são explicadas em termos de situação anterior ao século XVI. No caso da posição final, o valor fonético das letras $\underline{e}$ e $\underline{o}$ é discutido na história do português, por meio de argumentos diversificados, utilizados por alguns estudiosos. Alguns destes fatos apresentados por Naro (op. cit. p. 18) são reproduzidos e debatidos, sucintamente aqui, evidenciando um problema de determinação empírica.

(1) O $\underline{o}$ final aparece como $[\mathrm{u}]$ em palavras portuguesas tomadas de empréstimo pelo malaio no século XVI, como sepatu (sapato), Kedju (queijo), por exemplo (conforme HART, 1955 e HERCULANO DE CARVALHO, 1969 apud NARO, 1973). Esses fatos, contudo, são inexpressivos, a não ser quando acompanhados por uma consideração da porção relevante da estrutura da língua que recebe o empréstimo: 
Suponhamos, por exemplo, que a língua receptora apresentasse o $[\mathrm{u}]$ final átono, assim como [æ] ou algum outro som só distanciamente relacionado com [o]. Então se as palavras emprestadas viessem a ser bem assimiladas pela língua receptora, uma palavra que tivesse a forma [sapáto] na língua de origem se tornaria [sapátu] na língua receptora. Certamente se um estudioso quatro séculos mais tarde encontrasse a forma emprestada [sapátu] estaria enganado em concluir que a língua de origem também tivesse tido a forma [sapátu]. (NARO, 1973, p. 19)

Apesar do malaio do século XVI ser um mistério, crê-se que a proporção de palavras com $\underline{\text { }}$ é muito pequena em relação às palavras com $\underline{\mathrm{u}}$ (proporção de 29 palavras com -o contra 693 com -u). Outro argumento contra a interpretação de $[\mathrm{u}]$ para -o advinda do malaio é o fato de que o $u$ dessa língua ser encontrado tanto em sílaba tônica quanto átona.

(2) Transcrições fonéticas, em certas peças espanholas do século XVI, de $\underline{o}$ final escrito como $\underline{u}$ nas linhas destinadas ao português, indicariam pronúncia da época. A relação grafia/som não é necessariamente transparente e direta, mas é um indicativo de diferença fonética do /o/ no português e no espanhol, representada pelo uso de certa letra ou diacrítico.

(3) A geografia dialetal atestaria o emprego de [i] para o $\underline{e}$ final em dialetos do Algarve e em vários outros lugares, como, por exemplo, na Madeira, na ilha Faial nos Açores, em grande parte do Brasil e em Portugal, como se a pronúncia de [i] fosse de outrora e a de todo o território em que o português era falado. O argumento de Hart (apud NARO, 1973, p. 22) de que o [i] é usado em muitos pontos bem separados, cobrindo todo um território, refere-se ao século XVI. Naro (op. cit, p. 22) presume que Hart tem em mente que a realização do [i] do e final é que foi exportada e subsequentemente alterada em Portugal, embora não em outras partes. Esse ponto de vista não pode ser mantido, pois interpreta a mudança como se ela não fosse natural e surgisse independentemente em vários dialetos e em diferentes épocas.

Apesar da imprecisão de algumas gramáticas na descrição da ortografia de época e de registros de evidências não empíricas, é inegável, pela recorrência de indicações, a existência de pronúncias [i, u] para as letras $\underline{e}$ e $\underline{o}$ no português arcaico e médio.

Características da pronúncia da língua portuguesa surgiram com mais segurança, segundo Mateus et alii (2003, p.28), com as primeiras gramáticas, como a de Fernão de Oliveira, em 1536 e a de João de Barros, em 1540; com o primeiro dicionário de português-latim e latim-português de Jerônimo Cardoso, e com o livro Ortografia da Língua Portuguesa de Duarte Nunes Leão, em 1576. Especificamente, em Portugal, neste período clássico, as vogais átonas $\underline{e}$ e $\underline{o}$ alternavam-se com $\underline{i}$ e $\underline{u}$, respectivamente. Já em posição final, o $\underline{o}$ era pronunciado como $\underline{u}$. 
No século XVI, a grafia era denominada fonética. Entretanto, a escrita que procurava espelhar a pronúncia é difícil de ser comprovada pelo fato de as edições dos textos nem sempre conservarem as formas ortográficas originais (PAIVA, 1988, p. 33). Said Ali (1964, p. 35) levanta a questão de que nem todo registro gráfico tem fundamento na pronúncia, no caso, por exemplo, de registros de palavras como igual, idade e respectivos derivados, em que a letra $\underline{e}$ aparecer no lugar de $\underline{i}$, observando que o som inicial desses vocábulos sempre teria sido [i]. Entretanto, o autor defende a realização de [i] em início de vocábulos que eram grafados tanto com $\underline{e} \operatorname{como} \operatorname{com} \underline{i}$ ou $\underline{e}$, como é o caso da palavra igreja. $\mathrm{O}$ autor sugere que a pronúncia primitiva era $i$, nos textos antigos, pela sílaba ser átona.

Mattos e Silva (2001, p. 55), em busca de resposta para a questão de haver uma oposição entre /e/ e /i/ em posição final, no português arcaico, coloca que

nas origens do português falado parece ter havido uma oposição fonológica nesse par. O argumento fonológico para essa afirmativa está no fato de ter ocorrido a metafonia que deu origem à oposição nos perfeitos dos verbos de padrão irregular, já realizada quando o português aparece documentado, como em fiz/fez; estive/esteve; pus/pôs. Na $1^{\text {a }}$ pessoa havia um i final (do latim í) que condicionou o fechamento da vogal tônica; enquanto na $3^{\mathrm{a}}$ a vogal final seria /ę/ (do latim / $\mathrm{i} /$, que já no latim imperial seria /ę/ e por isso não metafonizou a vogal acentuada. No português arcaico ocorrem grafias do tipo pusi, puse, pose, etc. em que a vogal etimológica está representada. (Mattos e Silva, 2001, p. 55)

Em posição final, no exame das grafias a partir do século XIII, Mattos e Silva (op. cit. p. 55-56) afirma que a convenção da letra $\underline{e}$ é predominante no período arcaico, e a variação i e é esporádica. A grafia $i$ ocorreria, em geral, nos pronomes complementos ( $m e / m i$, te/ti, lhe/lhi); no morfema da $2^{\text {a }}$ pessoa do singular do perfeito -sti, em vez de -ste no morfema $i$ do imperativo, que se opõe ao presente do indicativo em alguns casos como curri, fugi, miti, em vez de corre, mete e foge. Tais grafias sugerem uma realização alta na vogal que favoreceu o fechamento do timbre da acentuada.

Por fim, Mattos e Silva (op. cit, p. 56) conclui que o alteamento completo das vogais aconteceu no período clássico, contrariamente à posição de Naro de que, no século XVI, as vogais deveriam ser ligeiramente levantadas, mas diferentes das realizações portuguesa [i] e [u]. Para a autora, desde o século XIII, /i/ e /e/ finais fundiram-se em um único fonema que admitiria diferentes realizações fonéticas, ora [e], ora [i], ora timbres intermediários. 
Em relação à variação gráfica do tipo u o, nos casos em que não está em jogo o fenômeno fonético de metafonia, o /ọ/ do latim /ǔ/ passaria a /u/ por assimilação à vogal alta /u/ da sílaba final. A forma mais frequente nos documentos mais recuados é com a letra $u$ que dará lugar à grafia $o$, segundo Mattos e Silva (2001)

Em suma, as vogais postônicas pareciam apresentar valores fonéticos distintos na evolução do português, por algumas evidências ortográficas e testemunhos de estudiosos. Entretanto, as opiniões sobre o início do processo de alteamento e o valor fonético são díspares. O Quadro 1 ilustra as controvérsias quanto ao surgimento de variantes altas para as vogais postônicas finais, segundo alguns autores.

\begin{tabular}{|l|l|}
\hline \multicolumn{1}{|c|}{ Autores } & \multicolumn{1}{c|}{ Início } \\
\hline Rosa Mattos e Silva & Século XIII \\
\hline Anthony Naro (1973) & Antes do Século XIV \\
\hline Paul Teyssier (1982) & Século XVI \\
\hline Révah (1959) & Século XVIII, no português brasileiro \\
\hline
\end{tabular}

Quadro 1: Alteamento da Vogal Postônica Final na História do Português segundo alguns autores

O valor fonético das vogais $\underline{e}$ e $\underline{o}$ e o aparecimento das variantes $\underline{i}$ e $\underline{u}$ na história do português ainda persiste como um problema, pois a relação grafia/som não é clara para se postular algumas conclusões. As descrições sincrônicas de fala das vogais podem servir de parâmetro e orientação para investigações de evolução de formas variáveis. Aliar esses dois pontos de vista analíticos contribui muito para o conhecimento da mudança em uma variedade linguística. Resultados de algumas pesquisas sobre o comportamento variável na fala do português brasileiro serão expostos a seguir.

\subsection{No Português Brasileiro}

Conforme Câmara Jr (1975b, p.33), as sete vogais /a, e, E, o, , u/ da posição tônica do português brasileiro são reduzidas, na posição postônica, em decorrência de um processo de neutralização de vogais médias e vogais altas, condicionado prosodicamente. A neutralização, conceito criado por Trubetzkoy (linguista do Círculo Linguístico de Praga do início do século XX) faz com que a oposição entre dois fonemas desapareça, ficando para cada uma um fonema em vez de dois.

No caso das vogais médias postônicas, Câmara Jr defende que a neutralização aplica-se somente à vogal média posterior /o/, em posição não-final e, em posição final, a neutralização ocorre nas duas vogais, mesmo que a grafia registre a letra $o$. 
Aí a grafia com $o$ ou $u$ é uma mera convenção da língua escrita, pois o que se tem, na realidade, é /u/ (nos melhores poetas brasileiros pérolas rima com cérula, estrídulo com ídolo e assim por diante (CÂMARA 1953, 135-6).

Ao contrário, há distinção entre /e/ e /i/, embora seja difícil encontrar pares opositivos mínimos (mas uma pronúncia */nu `miru/, para número, ou */tè pedu/, em vez de /tè 'pidu/, para tépido, é logo rechaçada). Já para a vogal átona final, seguida ou não de /s/ no mesmo vocábulo, há a neutralização entre /o/ e /u/ e entre /e/ e /i 1. Assim Bilac rima Argus com largos, Vênus com serenos, e um poeta paranaense, como Cruz e Sousa, rima o lat. clamavi com nave, o it. Bellini com define (CAMARA 1953, 129-30).

Estudos da fala do português brasileiro, que surgiram a partir do final da década de setenta, têm contribuído muito na descrição do comportamento fonético e fonológico de vários aspectos linguísticos e, em especial aqui, das vogais átonas, que têm sido alvo de diversos estudos. A vogal átona foi estudada, na perspectiva sociolinguística laboviana, com dados do português de várias regiões do Brasil. No Sul do País, na pauta pretônica, há estudos de harmonia vocálica (BISOL, 1981; SCHWINDT, 2002, entre outros); de síncope, em proparoxítonas (AMARAL, 2002) e de vogais postônicas não-finais e finais (Schimitt, 1987; Vieira, 1994, 2002; Espiga, 1997; Roveda, 1998; Carniato, 2000; Mileski, 2013).

Esses trabalhos sobre fala de comunidades linguísticas sul rio-grandenses chamam a atenção para o fato de que a neutralização, apontada por Câmara Jr. (1975b), na pauta vocálica da posição postônica, não ocorre categoricamente no sul do País, como ocorre no dialeto carioca por ele descrito. Além disso, a regra tem caráter variável e parece sofrer alguns condicionamentos linguísticos e sociais. A realização como [e] e [o] é uma marca característica de algumas comunidades da região do sul do Brasil.

Dentre as pesquisas, segundo Vieira (2002), há restrições contextuais para a realização de $[u]$ e de [i] no lugar de $\underline{o}$ e de $\underline{e}$ na posição postônica não-final e final. O contexto precedente é um dos fatores mais salientes. A consoante labial favorece a elevação de /o/, provavelmente em função do traço de labialidade, partilhado por esses segmentos (abób[u]ra, mesm[u]). Já para o /e/, o contexto precedente fricativas $s / z$ favorece a realização de [i] (prec[i]), e o contexto coronal (microfon[e]) tende a preservá-la ${ }^{2}$.

Além desses aspectos, Vieira (op. cit.) aponta, como fatores linguísticos importantes no comportamento da vogal média, o tipo de sílaba em que se encontra a vogal postônica final e a presença

2. Bisol (2010), ao analisar o alçamento de vogais médias pretônicas /e/ e /o/ em contexto no qual não há vogal alta na sílaba seguinte (sem motivação aparente), em palavras como boneca e pequeno, por exemplo, desconsidera um condicionamento fonético específico. 
de vogal alta na palavra. Palavras acabadas em sílaba fechada por soante tendem a preservar as vogais (nív[e]l, Coll $[\mathrm{o}] \mathrm{r}$ ), e a presença de uma fricativa /s/, tende a elevá-las (ant $[\mathrm{i}] \mathrm{s}, \operatorname{men}[\mathrm{u}] \mathrm{s})$. A presença de vogal alta também é relevante para /e/, tanto em posição não-final, como final (índic[i]), e para, /o/, só em posição final (motiv[u]).

Dentre os fatores sociais, selecionados como importantes estatisticamente, Vieira aponta o grupo geográfico da amostra, como significativo. Entre os três estados do Sul, há a seguinte ordem decrescente de elevação das vogais: Rio Grande do Sul, Santa Catarina, Paraná. Já o exame por cidade mostra comportamento diversificado, com destaque para a cidade de Curitiba (PR), como o local que mais preserva a vogal média, e Porto Alegre, ao contrário, como a cidade que mais a eleva, segundo Vieira (2002). Nesse aspecto, Schmitt (1987) não destaca a cidade de Porto Alegre, mas a etnia alemã, como a aplicadora da regra. A vogal /e/ também sofre algumas restrições lexicais para aplicação da regra de elevação que ocorre em núm[i]ro, mas não em vésp[e]ra, por exemplo.

As descrições das vogais postônicas na fala do sul do País parecem apontar para resultados semelhantes. Brescancini (2008) reúne trabalhos sobre vogais postônicas, realizados na fala do sul do País, por meio do banco de dados Variação Linguística do Sul do Brasil (VARSUL), para discutir o efeito dos métodos de descrição de regra variável sobre os resultados obtidos nas pesquisas, pela perspectiva de Bailey e Tillery (2002). Conclui que, apesar de alguns desses trabalhos diferirem quanto à origem dos dados e à constituição da amostra, os resultados referentes a contexto, presença de vogal alta e etnia mostram-se comparáveis e passíveis de uma generalização.

Mileski (2013, p. 141), que também acredita na linha de generalização de dados, amplia o quadro de estudos de Brescancini (op. cit.), confirmando os fatores favorecedores do alçamento das vogais átonas finais em outros estudos e na comunidade de fala de descendentes de poloneses de Vista Alegre do Prata-RS. No que se refere à vogal /e/, consoantes dorsais ([k, g, ¥]), precedendo /e/ átono final, favoreceram seu alçamento. No que se refere à vogal /o/, palavras com vogal alta na sílaba tônica foram favorecedoras da elevação.

O exame das vogais postônicas na fala mostra, indiscutivelmente, o comportamento efetivo do processo de elevação dessas vogais, que não é categórico, mas condicionado por fatores de ordem linguística e social. Nesse aspecto, os estudos diacrônicos corroboram esse resultado quando, a exemplo de Naro (1973), Mattos e Silva (2001) alega que

ao que ficou observado pode-se concluir pelo menos: é possível admitir algum tipo de variação regional (social também?) nessa posição, o que se pode inferir pela metafonia (quando reproduzida na grafia), consequência da alta final; tal fenôme- 
no fonético não teria ocorrido ao mesmo tempo e em toda a parte da área galego-portuguesa. (...). (MAtтos e Silva, 2001, p. 57)

Diante desse quadro variável da realização da vogal postônica final no sul do Brasil, serão levantados registros gráficos de vogais médias postônicas /e, o/ em fontes escritas do século XIX no Rio Grande do Sul, com a forma de vogais altas /i,u/ de modo a verificar seu comportamento na evolução da variedade gaúcha do português brasileiro. A investigação tem por intuito:

- verificar que retrato é possível fazer sobre as vogais médias /e, o/ postônicas em um recorte sincrônico oitocentista no português brasileiro, em especial, da variedade gaúcha;

- caracterizar o comportamento variável das vogais médias postônicas no século XIX, como evidência de mudança linguística.

\section{Novas Observações em Jornais Oitocentistas do Rio Grande do Sul}

Diante do problema do valor fonético das vogais postônicas na história do português, este trabalho tem caráter preliminar, no que diz respeito a descobertas empíricas em dados escritos oitocentistas. $\mathrm{O}$ levantamento grafológico do registro de vogais médias postônicas /e, o/ em fontes escritas antigas no Rio Grande do Sul, com a forma ortográfica $\underline{i}$ e $\underline{u}$, tem por intuito verificar a existência de registros ortográficos com as letras $\underline{i}$ e $\underline{u}$ em palavras que são registradas com $\underline{e}$ e $\operatorname{com} \underline{o}$ nos dias atuais, respectivamente.

\subsection{Jornais do Rio Grande do Sul no século XIX: caracterização do corpus}

O corpus utilizado para a investigação consiste de jornais gaúchos escritos no século XIX. Estes jornais estão catalogados, na sua maioria, em dois arquivos públicos de Porto Alegre: Comunicação Social Hipólito José da Costa (www.museudacomunicacao.rs.gov.br) e Arquivo Histórico de Porto Alegre Moysés Vellinho (http://ahpoa.blogspot.com.br). Representam, por sua quantidade e diversidade, um valioso acervo da memória escrita no Estado, que tem seus primeiros registros manuscritos no final do século XVIII.

Os jornais, como documentos de imprensa, surgem no Rio Grande do Sul, em 1827, quando D. Pedro I extinguiu a censura ditada pelo governo e pela igreja (SODRÉ, 1983). São mais de 162 títulos, publicados em diversas cidades gaúchas, divididos por gêneros políticos e informativos até 1912: Nos primeiros jornais publicados nesse Estado, a editoria é do proprietário do jornal, e as publicações são precárias e pouco qualificadas até 1835, quando explode a Revolução Farroupilha.

Seguem-se as fases revolucionárias até 1850 e a panfletária civil até 1900, quando os proprietários e editores de periódicos se alinham obrigatoriamente a algum dos partidos políticos existentes, 
por sobrevivência financeira, sem se configurar uma imprensa partidária. As imprensas industrial, empresarial, de massa e de divertimento se dão em sequência (HoHLFELDT, 2006).

Para a observação das vogais médias postônicas foram utilizados treze (13) jornais diferentes, divididos por ano de publicação: oito jornais de 1827 a 1843 e cinco de 1864 a 1891, totalizando 444 exemplares, aproximadamente. Esses jornais foram analisados na íntegra, uma vez que não possuem uma estrutura editorial fixa como a dos jornais de hoje. Apresentam-se normalmente de duas a quatro páginas, variando o tamanho da folha e a ideologia (a favor ou contra a causa farroupilha). Os assuntos abordados são variados, como informes oficiais do governo, anúncios de venda de escravos, remédios, propriedades, anedotas, correspondências, comunicações, entrada e saída de navios no porto, etc.

A circulação era de duas, raramente três vezes por semana. As seções não se mantêm as mesmas de exemplar para exemplar. Por isso, a leitura, na íntegra, fez-se importante.

A vida destes jornais era efêmera, raras vezes conseguindo vencer um período de dois anos de circulação. O jornal era o trabalho de um, dois, três indivíduos, sem local de redação. Em regra, o redator escrevia em sua própria casa o jornal, levava-o a uma tipografia, quando não possuía um pequeno prelo, e ele mesmo se incumbia da revisão, da distribuição (...) (Reverbel e Bones, 1996, p. 45)

Muitos desses Jornais trazem assuntos populares, como crimes, julgamentos, fuga de escravos, pedidos de aluguel e compra de escravos, entre outros, que constituíram, segundo Reverbel e Bones (1996, p. 25), uma das características mais marcantes da imprensa da época, como uma das primeiras fontes de renda do jornalismo brasileiro, com matérias pagas.

Cabe ressalvar que, neste trabalho, não serão tratadas questões relacionadas aos redatores e editores, por ser muito escassa e contraditória a documentação referente a eles. Apesar de ser importante traçar um perfil sócio-cultural de quem de fato escreve o jornal e de quem o lê, não é possível, para fins deste trabalho, entrar no mérito da questão.

Além de trechos publicitários, que podem ilustrar alguns dos problemas comunitários de época, os jornais revelam, em raras passagens, o tipo de pessoa que participa do jornal. O Jornal A Gazetinha (1891 a 1990), por exemplo, ilustrado a seguir, revela que seus registros são de pessoas de uma classe menos privilegiada da comunidade da época:

Os escriptores da "Gazetinha", sem excepção de um único, são todos elles homens pobres, alguns paupérrimos (...) Alguns dentre elles são simples operarios, que furtam diariamente algumas horas ao repouso, trocando a ferramenta pela penna,...”(A Gazetinha, 11/07/1898, p.1 - Cautella) 
Os títulos analisados estão expostos no Anexo, por ordem cronológica decrescente de lançamento. A maioria desses jornais faz parte da primeira fase da evolução da imprensa (de 1827 a 1850)른 de fundo ideológico e de liberalismo romântico. A fase seguinte, final do século XIX, situa-se na época de Júlio Castilhos ${ }^{4}$ com os jornais A Federação $(1884)^{5}$ e A Reforma (1869), através dos quais o sentimento abolicionista e o ideal republicano dominavam as páginas dos periódicos, caracterizados mais como partidários do que ideológicos.

Não há dúvida, pois, sobre o valor dos jornais como uma rica fonte de estudo sincrônico oitocentista. A diversidade de números e de assuntos, assim como a quantidade disponível nos Arquivos Públicos, faz-se importante para a história e a memória do Rio Grande do Sul.

\subsection{Registros Grafológicos de Vogais Postônicas em Jornais Oitocentistas do RS}

Os dados coletados mostraram que não há praticamente registros de vogais postônicas com a grafia $\underline{i}$ ou $u$, exceto nos seguintes vocábulos: quasílquazi (quase) - 75 registros; si (se) - 20 registros;

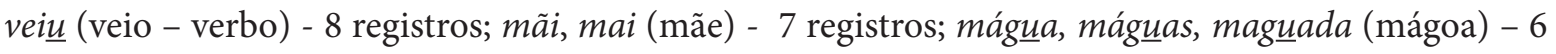
registros; agrícula (agrícola) - 2 registros. Com exceção do advérbio quase e da conjunção se, grafados preferencialmente com $\underline{\mathrm{i}} \mathrm{em}$ vez de $\underline{\mathrm{e}}$, praticamente em todos os jornais examinados, as demais formas encontradas restringem-se a certos títulos e exemplares, como grafias arbitrárias e variáveis ${ }^{6}$.

Os registros esporádicos encontrados das outras palavras registradas com $\underline{u}$ e com $\underline{i}$ foram obtidos nos seguintes jornais:

3. Segundo Barreto (1986), a primeira fase da história rio-grandense inclui 61 jornais editados em Porto Alegre e 37 na cidade de Rio Grande, aos quais devem ser incluídos os três órgãos da República Rio-Grandense - $O$ Povo, Americano e Estrela do Sul, publicados em Piratini, Caçapava e Alegrete.

4. Júlio Prates de Castilhos nasceu no Rio Grande do Sul, em 1860, em Vila Rica (nome atual da cidade é Júlio de Castilhos). Formado em Direito, foi jornalista e político. Foi um dos fundadores do partido Republicano e do jornal A Federação, tornando-se presidente da Província de São Pedro (RS) em 1891 e em 1893.

5. Segundo Reverbel e Bones (1996, p. 49), no ano de fundação do jornal A Federação (1884), circulavam 56 jornais, dos quais 18 diários: 5 na capital, 5 em Pelotas e 3 em Jaguarão.

6. O levantamento de dados nesta pesquisa não pode levar em conta o confronto quantitativo de vocábulos grafados variavelmente com $\underline{u}$ e $\underline{o}$ (mágua/mágoa) e com $\underline{i}$ e $\underline{e}$ (quasi/quase), pelo fato de não se dispor, até o presente, da transcrição de trechos dos jornais analisados em um arquivo em Word. Uma transcrição nesse formato facilitaria, diante do número expressivo de palavras existentes em todos os 444 exemplares examinados, um levantamento numérico de palavras registradas com $\underline{o} \mathrm{e} \operatorname{com} \underline{\underline{e}}$ em relação às formas gráficas procuradas $\underline{u} \mathrm{e}$ $\underline{i}$, respectivamente. 


\begin{tabular}{|c|c|}
\hline & Título do Jornal/Data de publicação \\
\hline veiu $($ veio - verbo) & $\begin{array}{l}\text { O Jornal do Commercio, 10/12/1867, 17/11/1868, } \\
\text { 19/11/1868; A Gazetinha, 15/11/1891 }\end{array}$ \\
\hline mãi/mai (mãe) & $\begin{array}{l}\text { O Constitucional Rio-Grandense, 24/09/1828; } \\
\text { America, 26/12/1870, 27/02/1870, 28/11/1870, } \\
29 / 08 / 1870,30 / 01 / 1871 ; \text { A Voz do Escravo, } \\
15 / 02 / 1881\end{array}$ \\
\hline máguaa, máguas, maguada (mágoa) & $\begin{array}{l}\text { Diario de Porto Alegre, 30/01/1815; O Jornal do } \\
\text { Commercio, 16/11/1867; América, 23/01/1871; A } \\
\text { Gazetinha, 24/01/1892, 13/06/1898,06/10/1898 }\end{array}$ \\
\hline agrícula (agrícola) & O Amigo do Homem, e da Pátria, 14/08/1829 \\
\hline
\end{tabular}

Quadro 2: Formas com Vogais Postônicas Grafadas com $\underline{\text { u }}$ e $\underline{\mathrm{i}} \mathrm{em}$ Jornais

Esses resultados permitem diferentes interpretações. Primeiro, os registros impressos dos jornais analisados não refletem a oralidade de um processo muito geral nos dias atuais, como é o caso de realizações de vogais finais como $[\mathrm{i}, \mathrm{u}]$ para os grafemas $\underline{e}$ e $\underline{o}$, respectivamente, confirmando a suposição de que não é possível se verificar o valor fonético dessas vogais pela grafia. Os poucos casos de registros de vogais altas $[i, \mathrm{u}]$ em vez de médias [e, o], encontrados em algumas palavras, podem indicar: a) reflexo de uma oralidade pouco expressiva ou incomum na época; b) registro acidental de representação de alteamento em vogais postônicas; c) inexistência de realização de [i, u] para as letras $\underline{e}$ e $\underline{o}$ em sílabas átonas

Uma evidência a favor da presença da pronúncia de vogal alta [i, u] na comunidade dessa época pode ser sugerida pelos casos de alteamento das vogais pretônicas, encontrados em outras palavras. A presença de registros escritos $\operatorname{com} \underline{i}, \underline{u}$ pode ser um indício de que há consciência fonológica do fenômeno do alçamento. São quantitativamente significativos ${ }^{7}$, nos jornais analisados, os casos de elevação vocálica de vogais médias pretônicas, provocados pela presença de uma vogal alta na sílaba subsequente, ilustrando caso do processo de harmonia vocálica, como nas palavras similhante (semelhante) ou riligião (religião), por exemplo, ou de alçamento diante de nasais ou sibilantes, como em $\underline{\underline{i} m \text { - }}$ possado (empossado) e dísgraçados (desgraçados). Há também palavras com $\underline{u}$ e $\underline{i}$, ilustrando a situação de alçamento sem motivação aparente, como, por exemplo, muleque (moleque) e rịcheado (recheado) ${ }^{8}$.

7. Entende-se neste trabalho a expressão quantitativamente significativa como forma recorrente em vários textos.

8. Bisol (2010) distingue dois casos de alçamento em pretônicas: harmonia vocálica, quando há uma vogal alta como gatilho para a elevação vocálica e o caso sem motivação aparente, quando há alçamento sem qualquer vogal alta na palavra. O primeiro tem motivação fonológica, e o segundo lexical. 
Os exemplos de situações de registros de $\underline{i}$ e $u$, que podem expressar fenômenos fonológicos, são variados e estão presentes em todos os jornais, sem exceção. O Quadro 3 a seguir traz os casos mais recorrentes encontrados.

\begin{tabular}{|l|l|l|l|}
\hline \multicolumn{1}{|c|}{$\begin{array}{c}\text { Processo } \\
\text { Fonológico }\end{array}$} & Harmonia Vocálica & \multicolumn{1}{|c|}{$\begin{array}{c}\text { Alçamento diante } \\
\text { de -N e-S }\end{array}$} & \multicolumn{1}{c|}{$\begin{array}{c}\text { Sem Motivação } \\
\text { Aparente }\end{array}$} \\
\hline & $\begin{array}{l}\text { cuzinha (cozinha) } \\
\text { dicidido (decidido) }\end{array}$ & $\begin{array}{l}\text { intender (entender) } \\
\text { intendeu }\end{array}$ & $\begin{array}{l}\text { cuberta (coberta) } \\
\text { encuberta } \\
\text { siquer (sequer) } \\
\text { Algumas formas } \\
\text { encontradas }\end{array}$ \\
$\begin{array}{l}\text { pulitico (político) } \\
\text { surrizo (sorrizo) }\end{array}$ & $\begin{array}{l}\text { sinão (senão) } \\
\text { disgosto (desgosto) }\end{array}$ \\
\hline
\end{tabular}

Quadro 3: Exemplos Frequentes de Registros Gráficos em Pretônicas em Jornais

Há também casos de grafias em pretônicas que poderiam ser explicados como registro etimológico, como é o caso da palavra entender, em que todas as formas derivadas aparecem escritas com -in (intendeu, intendido, intendedor, etc.), análogas ortograficamente à forma latina intendere. Esse tipo de situação é encontrada em textos oitocentistas, como reporta Barbosa (2005), podendo ser um indicativo de aferição de erudição do texto.

Os dados em pretônicas mostram, pois, que a oralidade pode estar retratada em textos oitocentistas. Entretanto, o valor fonético das vogais postônicas ainda é uma incógnita, já que a representação grafológica de vogais átonas médias como $\underline{i}$ e $\underline{u}$ é restrita a poucos casos. Por outro lado, é possível inferir que a falta de evidências empíricas na variação da grafia possa estar expressando uma consolidação da representação grafemática de vogais médias átonas como $\underline{e}$ e $\underline{o}$ na ortografia, uma vez que a elevação poderia ser uma regra geral na época oitocentista, como é nos dias atuais, na maior parte das variedades do português brasileiro.

Uma tentativa de justificativa para a não expressão da oralidade na escrita oitocentista, no caso das vogais postônicas, baseia-se na crença de que a relação letra/som não era mais problemática na escrita oitocentista, pois os registros de vogais átonas médias finais são preponderantemente encontrados com vogais $\underline{e}$ e $\underline{\underline{a}}$, assim como acontece nos dias atuais. Não é comum escrever vogais átonas finais com $i$ ou $u$, mesmo que sejam pronunciadas conforme o som que a letra sugere.

Reflexos de processos fonológicos e indícios fonéticos na escrita podem ser observados algumas vezes, mas nem toda oralidade é transparente na ortografia. Os "erros" ortográficos em redações escolares são, em sua maioria, de outra ordem fonética. Câmara Jr (1975a, p. 36) relaciona tendências de representações com vogais i/u apenas em pretônicas. Erros frequentes de registros de vogais finais também não são apresentados em outros trabalhos que examinam a interferência da oralidade na escrita, como pode ser visto em Mollica (2000), Abaurre (2006) e outros. 
A aprendizagem da escrita por crianças demonstra que esse tipo de "erro" na ortografia de vogais é superado desde cedo ou até inexiste em produções escritas iniciais. Segundo Miranda et alii (2005, p. 4), os erros encontrados na escrita decorrem, na maioria das vezes, da não biunivocidade entre letra/som/ fonema. Essa relação é mais estreita em relação às vogais, em que há a disposição de cinco grafemas para representar sete fonemas vocálicos, ao contrário do fonema /s/, que apresenta oito grafemas disponíveis para representá-lo. As crianças em fase inicial de escolarização fazem erros motivados pela fala, como em grafias como pirigu (perigo) e istrela (estrela), por exemplo, nos quais se vê claramente o funcionamento das regras de neutralização, manifestada pela forma ortográfica (op. cit, p. 5).

O português moderno registra a ortografia da vogal átona final com os grafemas -e e -o, independentemente da sua pronúncia. Como dito anteriormente, as diferentes realizações são neutralizadas na escrita, não se observando essa variação em dicionários atuais, contrariamente a outros processos fonológicos que apresentam variação de grafia, como flecha/frecha, corrupto/corruto, espírito/ esprito, por exemplo.

Câmara Jr. (1953, p. 129) atribui à convenção da língua escrita o fato de se escrever e/o em vez de i/u, ao evocar as rimas de poetas brasileiros, como em pérola/ cérula; estrídulo/ídolo; lat. clamavi com nave; it. Bellini com define. A perspectiva da relação letra som é apenas gráfica para Paiva (2008, p. 207), que interpreta as formulações na gramática quinhentista de Fernão de Oliveira sobre não se escrever $\underline{i}$ no lugar de $\underline{e}$.

A tradição ortográfica oitocentista no Brasil parece condenar a grafia i/u de vogais médias finais, conforme pode ser observado em um parecer feito em 1860, por José Alexandre Passos, sobre um livro utilizado em várias escolas e regiões do País ${ }^{9}$. O parecer analisa, entre outros aspectos, a ortografia utilizada no livro, condenando diversos registros com a grafia $\underline{i}$ por $\underline{e}$ em vogais pretônicas, conforme pode ser observado a seguir.

A mudança que faz o autor do Iris Classico, do -e- mudo de algumas palavras para -i, é contrária á índole da língua portugueza e reprovada por todos os nossos lexicographos. Elle escreve intender, idificar, intrar, inxertar, intregar, impenhar, incommendar, inganas, alem de outras, em vez de entender, edificar, entrar, enxertar, en-

9. José Alexandre Passos era um inspector parochial no século XIX que, a pedido do diretor de instrução pública da Província das Alagoas, Sr. José Correa da Silva Titara, exara um parecer analítico de um livro chamado ISIS CLASSICO, de autoria de Castilhos José, adotado pelas províncias da Bahia, Ceará, Espírito Sancto, Goyaz, Maranhão, Minas, Pará, Parayba do Norte, Pernambuco, Santa Catharina, Sergipe, Conselho de Instrução Pública da corte e Collegio Pedro II. O parecer, bem como a réplica a esse está disponível na biblioteca da Academia Brasileira de Letras, no Rio e Janeiro. 
tregar, encommendar, enganar. A mesma alteração faz nos substantivos e adjectivos, derivados desses verbos, contrariando assim a orthografia geralmente adotada; ao passo que muda o -i- para -e- nas palavras idade (...). (BARreto e Noronha, 1860, p. 10)

A prática ortográfica, em 1860, contudo, parece demonstrar que a variação gráfica entre e/i/ e o/u em vogais átonas aparecia em bons dicionários da época, conforme a defesa do autor do livro Isis Clássico, Castilho Jose, ao parecer exarado sobre sua obra em 02/07/1860. A variação gráfica e/i, assim como outras ortografias, estava presente na época.

(...) Assim justificada a anarchia dos dicionários do nosso idioma, direi que em centos e milheiros de palavras, eles mesmos deixam os consulentes indecisos entre 2,3 e 4 variantes (...). (BARreto e Noronha, op. cit., p. 199)

Havia, segundo Pagotto (2011), uma crise normativa na segunda metade do século XIX no português brasileiro. O parecer de Rui Barbosa na Comissão de Justiça do Senado, em relação ao projeto de Código Civil, originado na Câmara de Deputados, gerou uma polêmica de tomada de consciência da mudança dos padrões normativos, que vinha se registrando desde os anos de 1850. A discussão metalinguística sobre o Código deixa claro, segundo Pagotto, que

as formas linguísticas tomadas em variação não se submetem apenas às pressões sociais, entendidas como regras de comportamento no interior de uma dada comunidade linguística. É também a dimensão política (...) que toma de assalto as formas linguísticas, tensionando-as em uma certa direção (...). (РАGOTto, 2011, p. 162)

Por fim, a variação gráfica entre e/i e o/u em jornais oitocentistas sul rio-grandenses encontrada em periódicos constantes no Anexo não permite verificar o comportamento variável das vogais postônicas, pela escassez de dados. No entanto, há indícios grafológicos variáveis de alçamento em vogais pretônicas que evidenciam a instabilidade de realização das vogais médias átonas, que se encontra consolidada na norma escrita com e $\underline{e} \operatorname{com} \underline{\underline{o}}$, desde muito tempo, evidenciando neutralização entre dois sons, manifestada pela opção da escolha de um só grafema.

A analogia entre as posições pretônicas e postônicas, em termos de comprovação do processo de alteamento das vogais médias, pode ser um indício da existência da variação em vogais átonas. Os 
dados em jornais oitocentistas não parecem destoar da realidade grafemática de textos escritos em geral, como em redações escolares, em escritas de aprendizagem da escrita por crianças e em livros normativos de época. Talvez manuscritos, como cartas pessoais, por exemplo, possam disponibilizar dados mais concretos para outras suposições.

\section{Considerações finais}

As vogais médias postônicas /e/ e /o/ têm caráter variável na língua portuguesa falada moderna. No sul do Brasil, são realizadas como variantes médias $[e, o]$ ou altas [i, u] e sofrem interferência de fatores linguísticos e sociais. Na história da língua portuguesa, há controvérsias quanto ao reconhecimento dessas variantes e do início do processo de alçamento, que parece ser bem antigo, conforme alguns estudiosos.

Evidências são encontradas na grafia do português antigo, mas alguns casos são considerados equívocos grafológicos, com base na língua falada. Outros assemelham-se a situações encontradas na fala nos dias atuais. Como a grafia não representa com precisão os sons da fala, é difícil investigar a evolução de fenômenos variáveis por meio da escrita, restando apenas fazer especulações e interpretações, a partir de indícios.

Este artigo consistiu em um exame grafemático das vogais médias postônicas em situação de possível alteamento, em jornais oitocentistas produzidos nos Rio Grande do Sul. O levantamento de registros gráficos de palavras com $\underline{i}$ e com $\underline{u}$, no lugar de $\underline{e}$ e de $\underline{\underline{o}}$, em um número expressivo de jornais demonstrou que a representação ortográfica das vogais médias no século XIX, no Rio Grande do Sul, segue a convenção atual de registro com $\underline{e}$ e com $\underline{\underline{o}}$, salvo alguns casos, que se acredita que fogem à prática de escrita de época, tal qual ocorre nos dias atuais.

A presença abundante de grafias com vogais altas $\underline{i}$ e $\underline{u}$ no lugar das letras $\underline{e}$ e $\underline{\underline{ }}$, respectivamente, em contexto de vogais pretônicas, se comparada com a grafia de vogais postônicas, revela que o processo de alteamento de vogais médias estava operante na época oitocentista e que, analogamente, poderia existir também em outras posições. Entretanto, no caso de vogais postônicas, a ortografia neutraliza o valor fonético dessas vogais, deixando alguns resquícios em clíticos e em algumas poucas palavras, de forma arbitrária.

A investigação fonológica diacrônica enfrenta os obstáculos da representação letra/som, da incógnita sobre o reflexo da oralidade na escrita, entre vários outros problemas desse tipo de investigação. Entretanto, a investida do pesquisador para se estabelecer um filtro sobre os registros escritos, nos termos de Schneider (2002, p. 67), para a representação de um ato de fala supostamente ouvido, ainda é uma alternativa de análise a ser utilizada nos registros escritos oitocentistas no Rio Grande do Sul. 


\section{Artigo recebido: 28/08/2013}

\section{Artigo aceito: 25/11/2013}

\section{Referências}

ABAURRE, Maria Bernadete Marques. Dados de Aquisição da escrita: considerações a respeito de indícios, hipóteses e provas. Anais do Encontro Nacional de Aquisição da Linguagem. Porto Alegre:PUCRS, 2006.

AMARAL, Mariza Porto do. A síncope em proparoxítonas: uma regra variável. In: BISOL, Leda; BRESCANCINI, Cláudia. Fonologia e Variação: recortes do português brasileiro. Porto Alegre: EDIPUCRS, 2002, pp. 99-126.

BAILEY, Guy; TILLERY, Jan. Some Sources of Divergent Data in Sociolinguistics. In: FOUGHT, C. Sociolinguistic Variation: Critical Reflections. New York: Oxford University, 2004, pp. 11-30.

BARBOSA, Afrânio Gonçalves. "Tratamento dos Corporas de Sincronias Passadas da Língua Portuguesa no Brasil: recortes grafológicos e lingüísticos". In: LOPES, Célia. A Norma Brasileira em Construção: fatos linguísticos em cartas pessoais do século 19. Rio de Janeiro: Programa de Pós-graduação em Letras Vernáculas/FAPERJ, 2005.

BARRETO, Abeillard. Primórdios da Imprensa no Rio Grande do Sul. Porto Alegre, Comissão Executiva do Sesquicentenário da Revolução Farroupilha. Subcomissão de Publicações e Concursos, 1986.

BARRETO E NORONHA, José Feliciano de Castilhos. Orthographia Portuguesa. Missão dos Livros Elementares. Correspondencia Official, relativa ao ISIS CLASSICO. 2.ed. correcta e augmentada, Rio de Janeiro: Typ. E Livraria de B. X. Pinto de Souza, 1860.

BISOL, Leda. Harmonia Vocálica: uma regra variável. Tese (Doutorado em Linguística) - Faculdade de Letras. UFRJ, 1981.

. O português Brasileiro e o Português Brasileiro sob a perspectiva da neutralização. Palestra proferida no I Encontro Intermediário do GT de Fonética e Fonologia da ANPOLL, realizada na UFRGS em agosto de 2013.

BISOL, Leda; BRESCANCINI, Cláudia. Fonologia e Variação: recortes do português brasileiro. Porto Alegre: EDIPUCRS, 2002.

BRESCANCINI, Cláudia Regina. Sobre o efeito dos fatores estruturais na generalização de resultados: a elevação da vogal postônica em dados do Varsul. Fórum Linguístico. Florianópolis 5, v. 1, pp. 47-61, jan-jun, 2008.

CÂMARA Jr. Joaquim Mattoso. Para o Estudo da Fonêmica Portuguesa. Rio de Janeiro: Padrão, 1953. 
_. "Erros Escolares como Sintomas de Tendências Linguísticas no Português do Rio de Janeiro". Dispersos. Rio de Janeiro, Fundação Getúlio Vargas [1972] 1975a.

. Estrutura da língua portuguesa. São Paulo: Vozes, 1975b.

CARNIATO, M. C. A neutralização das vogais postônicas finais na comunidade de Santa Vitória do Palmar. Dissertação (Mestrado em Letras) - UCPel, 2000

ESPIGA, José. W. da R. Influência do espanhol na variação da lateral posvocálica no português de fronteira. 1997. Dissertação (Mestrado em Letras) - UCPeL, 1997.

HERCULANO DE CARVALHO, José G. C. Nota sobre o vocalismo antigo português. Revista Portuguesa de Filologia, 1962.

HOFELDT, Antônio. "A imprensa sul-rio-grandense entre 1870 e 1930". Revista da Associação Nacional dos Programas de Pós-Graduação em Comunicação. v. 7, Porto Alegre, PUCRS, 2006.

LABOV, Wiliam. Sociolinguistic Pattern. Philadelphia: University of Pensylvania Press, 1972

MARQUILHAS, Rita. Mudança Analógica e Elevação das Vogais Pretônicas. In: CASTRO, Ivo; DUARET, Inês (org.). Razões e emoção. Miscelânea de estudos em homenagem a Maria Helena Mira Mateus, 2. Lisboa: Imprensa Nacional/ Casa da Moeda, 2003, pp. 7-18.

MATEUS, Maria Helena M. et alii . Gramática da Língua Portuguesa. 5. ed, ver. e aum., Lisboa: Caminho, 2003.

MATTOS E SILVA, Rosa. O português arcaico: fonologia. São Paulo: Contexto, 2001.

MENON, Odete da S; MONARETTO, Valéria N. O. A legitimidade da metátese de róticos na história da língua portuguesa. Comunicação apresentada na ABRALIN 2009, João Pessoa, Paraíba.

MILESKI, Ivanete. A Elevação das Vogais Médias átonas Finais no Português Falado por Descendentes de Imigrantes Poloneses em Vista Alegre do Prata, RS. Dissertação (Mestrado em Linguístia) - Pontifícia Universidade Católica do RS, Porto Alegre, 2013

MIRANDA, Ana Ruth Moresco; SILVA, Michelle Reis da; MEDINA, Sabrina Zitzke . "O sistema ortográfico do português brasileiro e sua aquisição”. Linguagens \& Cidadania, v. 14, p. 1-15, 2005.

MOLLICA, Maria Cecília. Influência da fala na Alfabetização. 2. Ed. Rio de Janeiro: Tempo Brasileiro, 2000.

MONARETTO, Valéria Neto de Oliveira. "O estudo da mudança do som no registro escrito: fonte para o estudo da fonologia diacrônica”. In: Letras de Hoje, v.40, n. 3, pp.117-135, 2005.

NARO, Anthony J. Estudos diacrônicos. Petrópolis: Vozes, 1973. 
NASI, Roberto Francisco. Variáveis Fonológicas em Jornais Gaúchos do Século XIX. Dissertação (Mestrado em Linguística) - UFRS, Porto Alegre, 2012.

PAGOTTO, Emílio Gozze. "Rui Barbosa e a crise normativa brasileira”. In: CALLOU, Dinah; BARBOSA, Afrânio. A norma Brasileira em Construção: cartas a Rui Barbosa (1866 a 1899). Rio de Janeiro: Fundação Casa de Rui Barbosa. 2011, p. 107-166.

PAIVA, Dulce de Faria. História da Língua Portuguesa II: século XV e meados do século XVI. São Paulo: Ática, 1988.

PAIVA, Maria Helena. A descrição do vocalismo átono quinhentista: linhas e entrelinhas nos textos metalinguísticos coevos. Revista de Estudos Linguísticos da Universidade do Porto. Vol. 3, pp. 197-221, 2008 RÉVAH, I. S. Comment et Jusqu'à quell point les parlers brésiliens permettent-ils de reconstituer le système phonétique des parlers portugias des XVI-XVIII siécles? ACTAS, v. I. III Colóquio Internacional de Estudos Luso-Brasileiros. Lisboa, 1959

ROVEDA, Simone D. Elevação da vogal média átona final em comunidades bilíngues: português e italiano. 1998. Dissertação (Mestrado em Letras) - PUCRS, Porto Alegre, 1998.

REVERBEL, Carlos; BONES, Elmar. Luiz Rossetti: o editor sem rosto e outros aspectos da imprensa no Rio Grande do Sul. Porto Alegre: Copesul/L\&PM, 1996.

SAID ALI. Gramática Secundária da Língua Portuguesa e Gramática Histórica da Língua Portuguesa. ed. rev e atual. Brasília: Editora Universidade de Brasília, 1964.

SCHMITT, Cristina. J. Redução vocálica postônica e estrutura prosódica. 1987. Dissertação (Mestrado em Letras) - UFRGS, Porto Alegre, 1987.

SCHNEIDER, Edgar W. "Investigating Variation and Change in Written Documents". In: CHAMBERS, J. K.;TRUDGILL, P.; SCHILLING-ESTES, N. (ed.) The Handbook of Language Variation and Change. Malden/Massachusetts: Blackwell, 2002.

Schwindt, Luiz Carlos. A regra variável de harmonização vocálica no RS. In: BISOL, Leda; BRESCANCINI, Cláudia. Fonologia e Variação: recortes do português brasileiro. Porto Alegre: EDIPUCRS, 2002, pp. 99-126.

SODRÉ, Nelson. História da Imprensa no Brasil. São Paulo: Martins Fontes, 1983.

VIERA, Maria José B. Neutralização das vogais médias postônicas. Dissertação (Mestrado em Letras) UFRGS, Porto Alegre, 1994.

As vogais médias postônicas: uma análise variacionista. In: BISOL, Leda; BRESCANCINI, Cláudia. Fonologia e Variação: recortes do português brasileiro. Porto Alegre: EDIPUCRS, 2002, pp. 127-160. 


\section{ANEXO - Relação de Jornais Gaúchos do Século XIX Analisados}

\begin{tabular}{|c|c|c|c|c|c|}
\hline Título do Jornal & $\begin{array}{l}\text { Período de } \\
\text { Circulação }\end{array}$ & $\begin{array}{l}\text { Local de } \\
\text { Circulação }\end{array}$ & $\begin{array}{l}\text { Periodicidade/ } \\
\text { No de Páginas/ } \text { Formato }\end{array}$ & $\begin{array}{l}\mathrm{N}^{\circ} . \text { de } \\
\text { Exemplares } \\
\text { Analisados } \\
\text { (quantidade e } \\
\mathbf{n}^{0} \text { de jornal/ } \\
\text { data) }\end{array}$ & $\begin{array}{l}\text { Proprietário/ } \\
\text { Redator }{ }^{*}\end{array}$ \\
\hline $\begin{array}{l}\text { Diário de Porto } \\
\text { Alegre }\end{array}$ & $\begin{array}{l}01 / 06 / 1827 \text { a } \\
30 / 06 / 1828\end{array}$ & Porto Alegre & $\begin{array}{l}\text { terças-feiras a } \\
\text { domingos } \\
13 \times 29 \mathrm{~cm} \\
\text { folha dupla em } \\
\text { duas colunas }\end{array}$ & $\begin{array}{l}\mathrm{n}^{\text {os }} 88 ; 143 ; \\
172 ; 229-241 ; \\
447 \\
17 \text { exemplares }\end{array}$ & $\begin{array}{l}\text { Cláudio } \\
\text { Dubreuil } \\
\text { (impressor } \\
\text { e tipógrafo), } \\
\text { João Inácio } \\
\text { da Cunha } \\
\text { (1' redator), } \\
\text { Vicente } \\
\text { Ferreira Gomes } \\
\text { (2ºdator) }\end{array}$ \\
\hline $\begin{array}{l}\text { O Constitucional } \\
\text { Rio-Grandense } \\
\text { (Jornal Político e } \\
\text { Literário) }\end{array}$ & $\begin{array}{l}05 / 07 / 1828 \text { a } \\
26 / 03 / 1831\end{array}$ & $\begin{array}{l}\text { Porto Alegre, } \\
\text { Rio Grande, } \\
\text { Rio Pardo e } \\
\text { Pelotas }\end{array}$ & $\begin{array}{l}\text { quarta-feira e } \\
\text { sábado } \\
4 \text { páginas em } \\
\text { duas colunas }\end{array}$ & $\begin{array}{l}\mathrm{n}^{\mathrm{os}} 01-03 ; 06- \\
08 ; 10-50 ; 242 ; \\
248 \\
49 \text { exempl. }\end{array}$ & $\begin{array}{l}\text { Lourenço de } \\
\text { Castro Júnior, } \\
\text { Pedro José } \\
\text { de Almeida, } \\
\text { Cláudio } \\
\text { Dubreuil, } \\
\text { Vicente } \\
\text { Ferreira } \\
\text { Gomes. }\end{array}$ \\
\hline $\begin{array}{l}\text { O Amigo do } \\
\text { Homem, e da } \\
\text { Pátria }\end{array}$ & 1829 a 1831 & Porto Alegre & $\begin{array}{l}\text { terça, quinta e } \\
\text { sábado } \\
4 \text { páginas } \\
22 \times 32 \mathrm{~cm}\end{array}$ & $\begin{array}{l}\mathrm{n}^{\text {os }} 10-15 ; 17 \\
20,23-49,52- \\
55,57-81 \\
75 \text { exemplares }\end{array}$ & $\begin{array}{l}\text { Lourenço de } \\
\text { Castro Júnior, } \\
\text { Thomás Inácio } \\
\text { da Silveira, } \\
\text { Cláudio } \\
\text { Dubreuil. }\end{array}$ \\
\hline O Noticiador & $\begin{array}{l}03 / 01 / 1832 \text { a } \\
09 / 02 / 1836 ?\end{array}$ & Rio Grande & $\begin{array}{l}\text { terças e sextas- } \\
\text { feiras } \\
22 \times 32\end{array}$ & $\begin{array}{l}\mathrm{n}^{\circ} 02 \text { de } \\
06 / 01 / 1832\end{array}$ & $\begin{array}{l}\text { Francisco } \\
\text { Xavier Ferreira }\end{array}$ \\
\hline O Mensageiro & $\begin{array}{l}03 / 11 / 1835 \text { a } \\
03 / 05 / 1836\end{array}$ & Porto Alegre & $\begin{array}{l}\text { terças e sextas- } \\
\text { feiras } \\
22 \times 32 \mathrm{~cm}\end{array}$ & $\begin{array}{l}\text { de } 03 / 11 / 1835 \\
\text { a } 29 / 04 / 1836 \\
13 \text { exemplares }\end{array}$ & $\begin{array}{l}\text { Vicente Xavier } \\
\text { de Carvalho }\end{array}$ \\
\hline O Povo & $\begin{array}{l}01 / 09 / 1838 \text { a } \\
02 / 02 / 1839 \\
\text { (Piratini) e } \\
06 / 03 / 1839 \text { a } \\
23 / 05 / 1840 \\
\text { (Caçapava) }\end{array}$ & $\begin{array}{l}\text { Piratini } \\
\text { Caçapava }\end{array}$ & $\begin{array}{l}\text { quartas e } \\
\text { sábados } \\
4 \text { páginas } \\
20 \times 30 \mathrm{~cm} \text { e, mais } \\
\text { tarde, } 23 \times 34 \mathrm{~cm}\end{array}$ & $\begin{array}{l}\text { de } 24 / 10 / 1838 \\
\text { a } 09 / 03 / 1839 \\
14 \text { exemplares }\end{array}$ & $\begin{array}{l}\text { Luiz Rossetti e } \\
\text { Domingos José } \\
\text { de Almeida }\end{array}$ \\
\hline
\end{tabular}




\begin{tabular}{|c|c|c|c|c|c|}
\hline O Americano & $\begin{array}{l}24 / 09 / 1842 \mathrm{a} \\
01 / 03 / 1843\end{array}$ & Alegrete & $\begin{array}{l}\text { quartas-feiras e } \\
\text { sábados } \\
4 \text { páginas } \\
22 \times 32 \mathrm{~cm}\end{array}$ & $\begin{array}{l}\text { 24/09/1842 a } \\
01 / 04 / 1843 \\
18 \text { exemplares }\end{array}$ & $\begin{array}{l}\text { Propriedade } \\
\text { Nacional. } \\
\text { Cont. como } \\
\text { Estrella do Sul }\end{array}$ \\
\hline Estrella do Sul & $\begin{array}{l}04 / 03 / 1843 \mathrm{a} \\
15 / 03 / 1843\end{array}$ & Alegrete & $\begin{array}{l}\text { Quartas-feiras e } \\
\text { sábados } \\
22 \times 32 \mathrm{~cm}-4 \mathrm{p} .\end{array}$ & $\begin{array}{l}04 / 03 / 1843 \\
15 / 03 / 1843 \\
3 \text { exemplares }\end{array}$ & $\begin{array}{l}\text { Propriedade } \\
\text { Nacional }\end{array}$ \\
\hline $\begin{array}{l}\text { Jornal do } \\
\text { Commercio }\end{array}$ & $\begin{array}{l}1864 \mathrm{a} \\
01 / 11 / 1911\end{array}$ & Porto Alegre & $\begin{array}{l}49,5 \times 70 \mathrm{~cm} \\
4 \text { páginas }\end{array}$ & $\begin{array}{l}01 / 11 / 1867 \text { a } \\
01 / 01 / 1868 \\
34 \text { exemplares }\end{array}$ & $\begin{array}{l}\text { Luiz } \\
\text { Cavalcanti de } \\
\text { Albuquerque }\end{array}$ \\
\hline A Voz do Escravo & $16 / 01 / 1881$ & Pelotas & $\begin{array}{l}\text { quinzenal } \\
4 \text { páginas }\end{array}$ & $\begin{array}{l}\text { 16/01/1881 a } \\
15 / 07 / 1881 \\
6 \text { exemplares }\end{array}$ & ---- \\
\hline A Federação & $\begin{array}{l}01 / 01 / 1884 \mathrm{a} \\
17 / 11 / 1937\end{array}$ & Porto Alegre & $\begin{array}{l}\text { segunda-feira a } \\
\text { sábado } \\
4 \text { páginas/ } 8 \\
\text { páginas }(1912) \\
60 x 42 \mathrm{~cm}\end{array}$ & $\begin{array}{l}01 / 01 / 1892 \text { a } \\
04 / 04 / 1892 \\
12 \text { exemplares }\end{array}$ & Venâncio Ayres \\
\hline $\begin{array}{l}\text { America (Jornal } \\
\text { Noticioso, } \\
\text { Litterario e } \\
\text { Scientifico) }\end{array}$ & $1870-?$ & Rio Grande & $\begin{array}{l}\text { semanal } \\
\text { formato } \\
4 \text { páginas }\end{array}$ & $\begin{array}{l}\mathrm{n}^{\text {os }} 01-05 ; \\
09 ; 13-14 ; 17- \\
18 ; 22 ; 26-27 ; \\
30 ; 33 \\
15 \text { exemplares }\end{array}$ & $\begin{array}{l}\text { Zacarias } \\
\text { Salcedo \& M.J. } \\
\text { Estrella } \\
\text { Redatores } \\
\text { Diversos }\end{array}$ \\
\hline A Gazetinha & $\begin{array}{l}03 / 05 / 1891 \text { a } \\
03 / 1900\end{array}$ & Porto Alegre & $\begin{array}{l}\text { Quintas-feiras e } \\
\text { domingos } \\
60 \times 42 \mathrm{~cm} \\
4 \text { páginas }\end{array}$ & $\begin{array}{c}15 / 11 / 1891 \mathrm{a} \\
24 / 12 / 1898 \\
178 \\
\text { exemplares }\end{array}$ & $\begin{array}{l}\text { Octaviano } \\
\text { Manoel de } \\
\text { Oliveira } \\
\text { (membro da } \\
\text { Liga Operária } \\
\text { de Porto } \\
\text { Alegre) }\end{array}$ \\
\hline
\end{tabular}

\section{${ }^{*}$ Fontes:}

1) BARRETO, Abeillard. Primórdios da Imprensa no Rio Grande do Sul. Porto Alegre, Comissão Executiva do Sesquicentenário da Revolução Farroupilha. Subcomissão de Publicações e Concursos, 1986.

2) Jornais Raros do Musecom 1808-1924 - CD Institucional. 